\title{
O CONTEXTO HISTÓRICO DAS UNIVERSIDADES FEDERAIS NO BRASIL E A PARTICIPAÇÃO DE DOCENTES, DISCENTES E TÉCNICOS ADMINISTRATIVOS NO PROCESSO DE TOMADA DE DECISÃO NESSAS INSTITUIÇÕES PÚBLICAS.
}

\author{
Patricia Batista Gonçalves ${ }^{1}$, Mário Rosa dos Santos², Manoel \\ Rodrigues Chaves ${ }^{3}$, André Vasconcelos da Silva ${ }^{4}$
}

\section{Resumo}

O principal objetivo do presente trabalho é compreender a história das origens do ensino superior no Brasil e participação dos docentes no processo de gestão das universidades, intentando caracterizar e analisar as práticas gerenciais da gestão, com a participação da comunidade acadêmica e dos técnicos administrativos. Com o ensejo de abranger os pressupostos teórico-metodológicos utilizados para tal feitio, buscamos identificar o uso do método com leituras bibliográficas de obras que abordam esta temática. Esse estudo foi realizado nas Universidades Federais do Brasil. A investigação foi ampliada, utilizando-se referenciais teóricos, nos quais embasamos em autores como Fávero (2006), Carvalho (2011), Araújo e Pinheiro (2010) dentre outros tantos que contribuíram para fundamentar a realização deste trabalho. Os dados analisados revelam que o poder decisório está concentrado nas mãos dos docentes, e a maioria dos estudantes e dos servidores técnico-administrativos não participam dos órgãos deliberativos. Mediante esta abordagem, buscamos compreender a retrospectiva histórica e algumas particularidades da gestão universitária, tais como: aspectos burocráticos, fatores políticos, jogo de poder e a cultura que a universidade pública desenvolve, bem como o caráter contraditório e os enfrentamentos inerentes à gestão participativa.

Palavras-chave: conflitos, gestão participativa, Universidade.

\footnotetext{
${ }^{1}$ Pós-graduação em Gestão Organizacional-Regional Catalão/UFG. patricia.gol@ hotmail.com

${ }^{2}$ Sociólogo, aluno do Programa de Mestrado Profissional em Gestão Organizacional da Universidade Federal de Goiás/Regional Catalão, Técnico-Administrativo da Universidade Federal de Goiás/Regional Goiânia.mrosa8@gmail.com

${ }^{3}$ Geógrafo, Docente do Programa de Mestrado Profissional em Gestão Organizacional da Universidade Federal de Goiás/Regional Catalão. manoelufg@ gmail.com

${ }^{4}$ Professor Doutor no curso de Administração e do Programa de Mestrado Profissional em Gestão Organizacional da Universidade Federal de Goiás/Regional Catalão, Brasil. andre.silva.ufg@gmail.com
} 


\section{1. introdução}

O presente artigo abordará no contexto histórico o surgimento do Ensino Superior no Brasil, para a compreensão do processo de implantação, desafios e lutas que foram enfrentados desde a vinda família imperial para o Brasil até os dias atuais. Esse cenário servirá de alicerce para analisar e compreender o processo de gestão das universidades, assim como analisar as praticas gerenciais com participações dos docentes, técnicos administrativos e discentes.

O objetivo é refletir sobre as diversas interpretações e impasses da história da universidade no Brasil, como transformá-la em realidade concreta e qual o caminho a ser seguido por seus percussores. Em se tratando do referido tema, devemos refletir sobre estas questões, compreender a história do ensino superior e analisar a sua realidade cultural que eram oferecidas para a minoria da sociedade na época. Além disso, também tem-se por objetivo, identificar como se constitui o poder decisório nos conselhos superiores das universidades federais ao longo da história.

\section{Desenvolvimento}

\subsection{Historia Das Origens Do Ensino Superior No Brasil}

Souza(1991) discute que durante os trezentos anos, os únicos que tiveram interesse no campo do ensino foram os Jesuítas voltados para a catequização religiosa dos indivíduos. Apenas a elite da coroa portuguesa, os funcionários cargo superior da igreja e os filhos latifundiários com maior poder aquisitivo é que iam para Europa buscar formação superior.

Com a vinda da família real foi que ocorreram as primeiras ideias para criar as escolas de medicina nos Estados da Bahia e no Rio de Janeiro. Em fevereiro de 1808, surgiu o Colégio Médico-Cirúrgico da Bahia e em meados de abril a cadeira de Anatomia foi criada no Hospital Militar do Rio Janeiro.

Em 1810, o Príncipe Regente assinou a carta de lei de 04 dezembro, que estabeleceu a Academia Real Militar da Corte. Ao passar dos anos, esta foi transformada na Escola Politécnica e logo depois criaram-se uma Cadeira de Ciência Econômica e Academia das Artes. O ensino superior no país se consolidou nos modelos de institutos isolados e profissionalizantes. O que marcou de modo categórico o ensino superior no Brasil e explica as distorções que nos dias atuais estão balizando em nosso sistema (SOUZA, 1991).

Durante o século XIX, a partir da Proclamação da Independência, houve uma expansão de escolas superiores no Brasil. Tentaram criar a primeira universidade no país que apareceu, através de projeto de 1843, o qual visionava a construção da Universidade de Pedro II entre outras, que não saíram do papel (SOUZA, 1991).

Com a chegada da República ao Brasil, a responsabilidade do governo com a universidade foi omitida da Constituição de 1891. A partir de 1912, surge no Estado do Paraná a primeira universidade brasileira força local, mas após três anos de funcionamento foram fechadas as portas. Depois de muita luta, em 1920 criou-se a primeira Universidade do Rio de Janeiro oficial, que oferece os cursos superiores da região. Deferidas em três unidades tradicionais a saber: A escola Politécnica, a Faculdade Medicina e a Faculdade Direito de caráter profissional. O decreto que aprovou a universidade é o de $\mathrm{n}^{0}$ 14.343, de 7 de setembro de 1920 (SOUZA,1991). 
Dessa maneira, foram garantido autarquia administrativa e didática nas três unidades sem maior associação e cada qual com sua essência (FÁVERO, 2006). O elo destas universidade são a Reitoria e o Conselho Universitário. A problemática na criação dessas unidades trouxeram discussões para entidades tais como a associação Brasileira de Educação (ABE) e Academia Brasileira de Ciências (ABC). Segundo Fávero (2006), os assuntos que destacaram-se nos três debates foram: a concepção de Universidade e 0 trabalho que deveria caber nas universidade a ser adotado no Brasil.

Fávero (2006) tem dois tipos posicionamentos: a função básica a desenvolver a pesquisa científica e a formação profissional. Esses debates foram colocados para discussão na $1^{\circ}$ Conferência Nacional de Educação, em 1927, na cidade Curitiba, a partir da tese "As Universidades e a Pesquisa Científica", apresentada por Amoroso Costa.

O governo da época caracterizava-se na primeira Republica por descentralização, por política depois de 30 anos passou a crescer a centralização nos setores. Assim como na educação resolveu também elaborar e implementar medidas centralizadoras com valorização da formação de elite e na capacitação profissionalizante.

Para Fávero (2006), o Governo Federal criou seu projeto universitário com finalidade de articular medidas para a promulgação do Estatuto das Universidades Brasileiras com decretos referenciado às Universidade. Verificando o Estatuto das Universidades Brasileiras, Fávero (2006) mostra algumas questionamentos que merecem ser apontados.

Destacando o primeiro, refere-se à integração das escolas ou faculdades na nova estruturação universitária que pelo Estatuto se apresentam isoladas, dependentes da Administração superior. Outro apontamento de referência, à cátedra universitária, é a unidade operativa de ensino e pesquisa dos docentes. Este regime de cátedra ganha força com estatuto de maneira que fique na história com Constituições de 1934 e 1946, sendo substituída em 1968, posto que é extinta na organização do ensino superior, referente a Lei no 5.540/68(FÁVERO,2006).

A Universidade de São Paulo - USP foi um exemplo de luta pelos direitos adquiridos frente ao Governo Provisório seu autoritarismo após a Revolução Constitucionalista de 1932. Fávero (2006) expressa que aconteceu posições de contrastes e algumas que se destacam foram a Universidade de São Paulo (USP) EM 1934 e a Universidade do Distrito Federal (UDF) e assim que apareceram as finalidades das duas universidades foi um marco na historia do Brasil. As duas despontam denominação científica e uma posição totalmente diferente das outras universidades do pais.

Nesse novo cenário da universidade segundo Sousa (1991), a USP tem como elo a Faculdade Filosofia, Ciência e Letras, que seria a instituição do saber principal de todas as áreas do conhecimento humano e separado as faculdades localizadas na unidade (SOUZA 2016).

A partir do novo Governo, Autonomia era impraticável devido ao regime autoritário da época, na ocasião, o ministro Anísio Teixeira é desligado do cargo em nome da ordem e da disciplina. Em 1930 a UDF é extinta e os cursos ofertados são transferidos para nova Universidade do Brasil (UB) que foi criada (Lei 542/37), tanto o reitor e os diretos da unidade de ensino foram escolhidos pelo Presidente da República, de os concernente catedráticos, nomeados em comissão e os docentes e os alunos são proibidos de quaisquer tipos de manifestações político-partidários (FÁVERO2006).

Com a destituição de Getúlio Vargas em 1945, deu-se fim ao Novo Estado, o "marco da redemocratização do país" e tornou-se pública a nova constituição que de modo geral passou a ter um viés mais liberal em seus enunciados, tais como a "declaração de direitos" e especialmente no que trata "dos direitos e das garantias individuas". O Governo Federal aprovou o Decreto-lei em 1945 que "oferece autonomia administrativa, financeira, didática e disciplinar à UB e dá outras providências." O reitor passou a ser 
"nomeado pelo Presidente da República, dentre os professores catedráticos efetivos, em exercício ou aposentados, eleitos em lista tríplice e por votação uninominal pelo Conselho Universitário". E percebe-se que essa autonomia outorgada às universidades é uma mera ilusão analisando os documentos disponíveis no que diz respeito à autonomia universitária, apesar de apresentar um avanço para UB (FÁVERO, 2006).

A partir das décadas de 50 e 70, conforme Souza(1991), criaram-se as universidades federais em todo o país, sendo uma em cada estado. A implantação da descentralização do ensino superior foi a linha seguida na lei de Diretrizes e Bases da Educação Nacional. A criação da Universidade de Brasília (UNB), surge como divisor de águas na história universitária (FÁVERO, 2006).

Aconteceu uma grande movimentação pela atualização do ensino superior no país, entidades como a UNE passaram a lutar pelas Diretrizes Reforma Universitária,mas com o golpe militar de 1964, essas diretrizes foram suspensas.

O Ministro da Educação em 1966, dirige mensagem ao Conselho Federal de Educação (CFE) requerendo a incorporação dos estudos executados na Universidade do Brasil em relação à reformulação de sua base. Nessa época apareceram outras medidas que foram adotadas em relação às universidades e algumas delas merecem ser ressaltadas: o plano de assistência técnica estrangeira, consubstanciado pelos acordos MEC/USAID; o Plano Atcon(1966) e o Relatório Meira Mattos (1968).

O consultor americano faz orientações para Reformulação Estrutural da Universidade Brasileira, publicado pelo Mec em 1966, recomendou que se ajustasse tanto o ensino superior quanto as instituições de acordo com necessidade do país. É aprovado o Projeto de Reforma Universitária em 1967, a fim revigorar o princípio de autoridade e disciplina nas instituições, aumentar o número de vagas, estabelece o vestibular unificado, geração de cursos de curta duração(FÁVERO, 2006).

A crise da Universidade, Segundo(FÁVERO, 2006) foi aprovada pelas manifestações estudantis e populares cujo o foco foi exigir respostas sobre tudo para questões do excedentes. Em razão disso, foi criado um Grupo de Trabalho (GT) para estudar medidas mais urgentes em relação a vestibular unificado, sistema de créditos e a matricula por disciplina em substituição ao modelo anual para semestral. A crítica mais efetiva foi feita em relação aos departamentos como local de burocracia dos docentes.

Conforme exposição de Souza(1991) o ensino universitário atingiu seu ponto de máximo da década de 70 , quando houve aumento muito significativo para o numero de matricula. Isso motivado pelo fluxo urbano exigindo mão de obra qualificada, o que provocou a medida do Governo para aumentar o número de vagas que fez com que o Conselho Federal de Educação desse aprovação para cursos novos; essas medidas proporcionaram a mudança nos tipos de provas que antes eram dissertativas e passaram a ser de múltipla escolha.

Para reestruturar e expandir as Universidade Federais foi Criado - REUNI (Plano de Reestruturação e Expansão das Universidades Federais) instrumento destinado a fornecer recursos tanto para ampliação de número de vagas com também diminuir evasão de discentes e melhorar a estrutura física e humana.

Concluída essa bordagem Araújo e Pinheiro (2010) ressaltam que mesmo desenvolvendo essas novas ações, o REUNI torna-se um agente responsável por essas novas etapas de expansão das IFES, pela realização grande parte dos investimentos, assim como nova reestruturação interna. Ainda na visão dos referidos autores Araújo e Pinheiro (2010) esse plano objetiva dar respostas para o novo modelo de gestão buscando maior eficácia para os gastos públicos em universidades e não se pode negar que transformação foram feitas. 


\subsection{Participação No Processo De Gestão Das Universidades}

\section{Vamos especificar alguns conceitos básicos para analisar como funciona a participação da comunidade universitária nos procedimentos das decisões nas universidade, como objeto de estudo a Universidade Federais.}

Carvalho(2011) na sua tese de doutorado refere-se o processo de gestão e participação na Universidade Federal do Tocantins, analisando os pensamento os autores que examinar essas questões. De acordo Chaui(2006) as ideias são descentralizar o poder e democratizar as decisões políticas para que a sociedade participe desses movimentos antagônicos. Ao infere Carvalho(2011) estas instituições são marcadas por desigualdades e contradições em sua administração, com isso demostrar os resultados importante para o processo de participação.

Para Carvalho(2011) o autor tenta aclarar as possibilidades e limites de tal participação na forma mais elementar e esse estudo e a concepção gramsciana de democracia de participação de uma luta constante da sociedade e de suas instituições contra politica travada. Este estudo conduz à reflexões a respeito de como é importante compreender as eleições políticas. De igual maneira, é importante a participação da sociedade na escolha dos dirigentes como presidente da República, do diretor e do coordenador de escolas, do reitor da universidade, dentre outras. Segundo Carvalho(2006) o exercício da participação efetiva dos sujeitos nela envolvidos pode ajudar a colaborar para o mecanismo de autonomia.

Em consequência de oferecer uma perspectiva de administração mais democrática, a luta por uma efetiva participação na universidade pública brasileira, particularmente nas IFES. Trata-se de uma comunicação clara, além de transparência a respeito dos condicionantes institucionais mais abrangentes, os problemas, as dificuldades, 0 planejamento, a execução e a avaliação dos processos educativos. Esse tipo de informação envolve os canais de consultas consensuais, mas não exclui a participação direta, as reivindicações e os protestos (CARVALHO, 2006).

As questões apresentadas acima, Carvalho(2006) Aparecem algumas dificuldades de natureza política com principais destaques as condições de trabalho precários e falta de recursos para desenvolver atividades necessárias dentro da universidade. Tais desigualdades podem entravar, apesar de não impedir a participação no processo de gestão das instituições.

Outro empasse indicado por Carvalho(2006) é referente às instituições que podem se organizar verticalmente em relação ao poder superioridade dos dirigentes que tomam as decisões e repassam aos dirigidos que estão e uma patamar de inferioridade. A relação de poder existente no sentido de ampliar os mecanismos institucionais que permitem estimulem a participação autonomia, mas não e simples essas problemáticas. Conforme Carvalho(2006) percebe-se que a gestão democrática somente ocorrerá no reconhecimento e respeito ao pluralismo e ao diálogo. E uma dessa perspectiva de gestão participativa é a luta por uma efetividades da universidades que traz a comunicação clara e um legitimo diálogo entre as partes.

É necessário redefinir as relações de poder para avançar no caminho da construção efetiva da democracia transparente. Nesse modelo de participação são os professores que têm a maior parte representativa, que decidem que rumo as universidades devem tomar. A maioria dos estudantes e servidores não participam dos órgãos deliberativo, com exceção dos departamentos e colegiados de cursos, cujo o poder deliberativo é limitado (CARVALHO, 2006). 
Os membros da comunidade universitária terão o ensejo de discutir e decidir a gestão que aborda o desenvolvimento das atividades e planejamento. Desse modo, o professor tem mais poder de decisão no destinos da instituição do que universitários e TAE nas tomadas de decisões do processo de gestão participativa.

Somente no final dos anos 70, os TAE conseguiram se organizar politicamente e conquistando o seu espaço na universidade mostrando a sua importância para comunidade acadêmica, mas as figuras dos docentes predominaram no poder de decisão superior em qualquer assunto, de acordo com paragrafo único artigo 56 da LDB 9.394/1996 (Carvalho,2006).

\section{CONSIDERAÇÕES FINAIS}

Ante o estudo, foi possível perceber que houve uma reestruturação do poder político e decisório. Desse modo, é evidente uma limitação aos técnicos administrativos, frente ao poder dos docentes na gestão da universidade. Por isso, é importante discutir, dentro das academias, a valorização do trabalho desses técnicos administrativos na participação das tomadas de decisões.

Buscando compreender os documentos apresentados no que diz respeito à autonomia concedida à Universidade do Brasil, analisa-se que isso nunca se convalesceu. Logo, a autonomia outorgada às universidades não passa, muitas vezes, de uma mera ilusão, embora se apresente, por vezes, como um avanço.

\section{HISTORICAL CONTEXT OF FEDERAL UNIVERSITIES IN BRAZIL AND TEACHERS, STUDENTS AND TECHNICAL ADMINISTRATIVES PARTICIPATION IN THE DECISION PROCESS IN SUCH PUBLIC INSTITUTIONS.}

\section{Abstract}

The main goal of present article is understanding of the history of the origins of higher education in Brazil and teachers' participation in the management of universities process intending tu characterize and analyze the managerial management practices, with the participation of academic community and the administrative technical. With the opportunity to cover the theoretical and methodological assumptions used for this shape, we seek to identify the use of the method with literature readings of works that address this issue; this study was conducted in the Federal Universities of Brazil. The investigation was expanded using theoretical frameworks that we utilize authors like Fávero (2006 ) , Carvalho ( 2011), Araújo and Pinheiro ( 2010) among many others who have contributed to support this work. The analyzed data show that the decision-making power is concentrated in teachrs' hands and most students and technical administrative staff that do not participate in decision-making bodies. Through this approach, we seek to 
understand the historical background and some particularity of university management, such as bureaucratic, political factors, power play and culture that the public university develops, as well as the contradictory character and the confrontations inherent in participatory management.

Keywords: conflicts. participative management. University.

\section{Referências}

ARAÚJO, Maria Arlete Duarte; PINHEIRO, Helano Diógenes. Reforma gerencial do Estado e rebatimentos no sistema educacional: um exame do REUNI. Ensaio: Avaliação e Políticas Públicas em Educação, vol. 18, núm. 69, octubre-diciembre, 2010, pp. 647-668.

FÁVERO, M. L. A. A Universidade no Brasil: das CARVALHO, R. F.(2011). O processo de gestão e participação na universidade: limites, possibilidades e desafios na UFT. (Tese de doutorado). Universidade Federal de Goiás, Goiânia, Goiás, Brasil. Recuperado de: http://ppge.fe.ufg.br/up/6/o/Tese_Roberto_Francisco.pdf.igens à Reforma Universitária de 1968. Educar, Curitiba, n. 28, p. 17-36, 2006. Editora UFPR.

CARVALHO, R. F.(2011). O processo de gestão e participação na universidade: limites, possibilidades e desafios na UFT. (Tese de doutorado). Universidade Federal de Goiás, Goiânia, Goiás, Brasil. Recuperado de: http://ppge.fe.ufg.br/up/6/o/Tese_Roberto_Francisco.pdf. CARVALHO, R. F.(2011). O processo de gestão e participação na universidade: limites, possibilidades e desafios na UFT. (Tese de doutorado). Universidade Federal de Goiás, Goiânia, Goiás, Brasil. Recuperado de: http://ppge.fe.ufg.br/up/6/o/Tese Roberto Francisco.pdf.

SOUSA, A. P. N. Dimensões organizacionais da Universidade Federal do Pampa: uma análise qualitativa da estrutura multicampi. 2015. $170 \mathrm{f}$. Dissertação (Mestrado Profissional em Gestão Organizacional) - Regional Catalão, Universidade Federal de Goiás, Catalão. 2016. 
